\title{
PAULO FREIRE: O ROUSSEAU DO SÉCULO VINTE: A ESSÊNCIA DE SUAS IDEIAS SOBRE ALFABETIZAÇÃO E LIBERTAÇÃO DO PONTO DE VISTA DE UM INDIANO E A PERSPECTIVA DO TERCEIRO MUNDO ${ }^{1}$
}

DOI: 10.48075/ri.v23i1.26704

Asoke Bhattacharya ${ }^{2}$

RESUMO: Paulo Freire, como filósofo, associou a alfabetização à libertação e, como pedagogo, apresentou inovações revolucionárias nas técnicas de alfabetização de adultos. Em seu método único, uma pessoa analfabeta poderia ser alfabetizada em um período de trinta horas. A evolução da epistemologia freireana foi atribuída às condições de vida no Nordeste brasileiro. Muitas das ideologias de Freire estavam enraizadas na história do Brasil. A colonização do país pelos portugueses e a forma como a população indígena foi submetida ao trabalho escravo e, posteriormente, a importação de milhões de escravos africanos para trabalhar nas plantações provocaram profundas feridas psicológicas nas relações humanas. Escravidão, a forma mais degradante de relação social e econômica juntamente com a união sexual do senhor com o escravo trouxe uma espécie de sadismo por parte da supremacia branca e certo masoquismo por parte de indígenas e africanos. Mesmo após a abolição da escravidão (1888), o sadismo e o masoquismo continuaram assombrando a sociedade brasileira. As cicatrizes eram bastante visíveis durante o tempo de Freire, razão pela qual ele caracterizou a realidade do Brasil como 'opressora'. Apesar de tanto a humanização quanto a desumanização serem alternativas reais, apenas a primeira pode ser a 'vocação' do povo, e mesmo sendo constantemente negada, é afirmada por essa mesma negação, conjecturou Freire. A história do Brasil nos últimos quinhentos anos tem sido estudada; foi investigado como as várias fases de sua história resultaram na formulação da teoria e na prática de Freire sobre alfabetização e libertação. Por fim, foi explorada a aplicabilidade de sua teoria e pedagogia no campo da educação de adultos em outros países do terceiro mundo, incluindo a Índia.

Palavras-chave: Paulo Freire, Brasil e Terceiro Mundo.

\section{PAULO FREIRE: THE ROUSSEAU OF THE TWENTIETH CENTURY: HIS ESSENTIAL IDEAS OF LITERACY AND LIBERATION AS SEEN FROM AN INDIAN AND THIRD WORLD PERSPECTIVE 3}

\footnotetext{
${ }^{1}$ Tradução de Bianca Lima Alessi.

2 Diretor do Instituto de Aprendizagem ao Longo da Vida de Bangladesh, Dhaka, Bangladesh. Ex professor e chefe do Departamento de Educação Continuada e Extensão para Adultos da Universidade de Jadavpur, Calcutá, Índia e recebeu o prêmio UNESCO-NLM pela contribuição notável no campo da alfabetização. Foi bolsista Erasmus Mundus da União Europeia na Escola de Educação da Universidade de Aarhus, Dinamarca. Escreveu vários livros, incluindo 'Educação para o Povo: Conceitos de Grundtvig, Tagore, Gandhi e Freire (Sense Publishers, Rotterdam, Boston, Taipei, 2010), Paulo Freire: Rousseau do século XX. (Sense Publishers, Rotterdam, Boston, Taipaei, 2011) e " Educação, Comunicação e Aprendizagem ao Longo da Vida (Sanket, Calcutá, 2014).Email: asokebhattacharya@yahoo.co.in

${ }^{3} \mathrm{O}$ artigo foi publicado pela primeira vez em [Pioneers in Education: Essays in Honor of Paulo Freire]"Pioneiros na Educação: Ensaios em homenagem a Paulo Freire" em tradução livre. Editores: Michael F. Shaughnessy, Elizabeth Galligan e Romelia Hurtado de Vivas. Nova Science Publishers, Inc. New York.2008.
} 
ABSTRAC: As a philosopher, Paulo Freire connected literacy with liberation and as a practitioner, he brought about revolutionary innovations in the techniques of imparting literacy to the adult illiterate.In his unique method, an illiterate person could gain literacy within a period of thirty hours. The evolution of Freirean epistemology was traced to the condition of living of the majority of the people in Northeast Brazil.Many of Freire's ideas had their root in the history of Brazil.The colonization of the country by the Portuguese and the way the indigenous population was subjected to enslaved labour and later the importation of millions of African slaves for work in the plantations -- brought about profound psychological aberrations in the human relations.Slavery, the most degrading form of social and economic relationship and the sexual union of the master and the slave brought about a species of sadism on the part of the white master race and masochism on the part of the Indian or African.Even after the abolition of slavery (1888), the sadism and masochism continued to haunt the Brazilian society.The scars were quite visible during Freire's time.This is the reason why he characterized the reality of Brazil as 'oppression'. While both humanization and dehumanization were real alternatives,only the first could be the people's 'vocation' but it was constantly negated, yet it was affirmed by that very negation, conjectured Freire. The history of Brazil over the last five hundred years has been studied; how the various phases of its history resulted in formulation of Freire's theory and practice about literacy and liberation has been investigated .Lastly, the applicability of his theory and practice in the field of adult education to other third world countries including India has been explored.

Key Words: Paulo Freire, Brazil and Third World.

\section{INTRODUÇÃO}

Paulo Freire tem sido chamado de Rousseau do século vinte por seu conceito de educação como prática da liberdade. Seu trabalho sobre métodos de ensino e a pedagogia do oprimido resultou em uma mudança qualitativa na filosofia e na prática da educação de adultos. Como um filósofo, ele relacionou literatura com libertação e, como um pedagogo, ele apresentou inovações revolucionárias nas técnicas de apresentação da literatura para adultos analfabetos. Em seu método único, uma pessoa analfabeta poderia ler em um período de trinta horas.

Paulo Freire contribuiu para a base filosófica da educação de adultos. Essa educação, sobretudo literária, costumava ser equiparada com a alfabetização. Se, através da alfabetização, uma pessoa pudesse colocar sua assinatura em papéis, identificar nomes de ruas e números de ônibus e realizar outros trabalhos, isso seria considerado uma conquista. $\mathrm{Na}$ Índia, pessoas alfabetizadas veem a educação de adultos com perspectiva limitada. Freire descartou todas essas noções. Ele relacionou alfabetização com civilização e cultura humana com libertação mental e física. 
Freire definiu o conceito de educação autêntica a partir de seu conceito de alfabetização como porta de entrada para libertação. Como a concepção de Einstein sobre o espaço-tempo, Freire inovou a percepção da relação professor-estudante e estudanteprofessor. Essa metamorfose revolucionária dos conceitos de ensinar e aprender resultou no compartilhamento recíproco de conhecimento entre coordenadores e participantes dos 'cícrulos de cultura', do qual todos participam das discussões com a finalidade de transformar a realidade existente e refletir acerca da sociedade em que vivem.

A evolução epistemológica Freiriana pode ser disposta de acordo com as condições de vida no Nordeste brasileiro. Muitas das ideias de Freire têm suas origens no período de colonização da história brasileira. A condição de vida da maioria da população era extremamente precária. Essas pessoas eram insultadas e humilhadas, torturadas e oprimidas. $O$ interesse de Freire era de auxiliar em sua luta pela libertação: não apenas da opressão física, mas também da subjugação mental.

Nesse artigo trataremos brevemente das condições do Brasil conforme os séculos. $E$ então abordaremos os principais conceitos de Freire acerca da alfabetização. Finalmente, investigaremos quão relevantes são suas ideias para países do Terceiro Mundo, especialmente para Índia.

\section{O CONTEXTO HISTÓRICO}

Foi em cerca de 1530 que a organização brasileira econômica e social começou a assumir uma forma definida. Durante os cem anos anteriores, os Portugueses estiveram em contato com outras nações dos continentes Ásia e África. Esse conhecimento de outros povos e culturas contribuiu para moldar atitudes dos Portugueses como colonizadores. Assim, no Brasil, por força das circunstâncias, eles estabeleceram um modelo agrícola e patriarcal de colonização. (FREYRE, 1970, p.3) A prática da escravidão importada do país de origem se tornou o principal modo de produção. (FREYRE, 1970, p.4) O cultivo da cana-deaçúcar começou na costa leste, nas regiões de São Vicente e Pernambuco. Uma aristocracia escravocrata se desenvolveu nas zonas de produção canavieira. O mesmo padrão prevaleceu nas regiões mineradoras e posteriormente nas plantações de café.

A sociedade, que era baseada na relação desigual entre a supremacia branca e indígenas ou escravos negros, originou uma doença social e física, esta devido ao surto de 
sífilis. E a escravidão, a forma mais degradante de relação social e econômica, juntamente com a união sexual de mestre e escravo gerou uma espécie de sadismo por parte da supremacia branca e masoquismo por parte de indígenas e africanos. Mesmo depois da abolição (1888), esse sadismo e masoquismo continuam a assombrar a sociedade brasileira. As cicatrizes permanecem visíveis no Brasil contemporâneo. (FREYRE, 1970, p.350)

Durante o período inicial do domínio Português, crianças indígenas do sexo masculino, que tivessem acabado de desenvolver dentes de leite, costumavam ser levadas do colo de suas mães por padres. Essa criança cresceria para se tornar o eixo da atividade missionária. Era ela, criada pelo padre, que se tornaria o ser ideal. Com o tempo, esse então rapaz seria o cúmplice do invasor durante a retirada dos "ossos" da cultura nativa. Então, desprovidos de suas características nativas, os povos indígenas seriam assimilados ao padrão da moralidade católica.

O jovem indígena era tanto mestre quanto discípulo. O padre, enquanto conversava em latim com o menino, estava aprendendo Tupi, a língua nativa dos indígenas. Assim, o padre tinha uma visão dos costumes sociais e da cultura indígena. O menino enquanto "criança da conexão" entre duas culturas também era o professor de seus pais e anciões. (FREYRE, 1970, p.164).

Todo brasileiro carrega consigo a sombra dos povos indígenas ou da raça africana. $\mathrm{Na}$ música, na fala, no deleite dos sentidos, no andar, nas canções de ninar, o brasileiro carrega a marca dessa influência; da escrava ou babá que balançou, amamentou e alimentou; a influência da velha senhora que contou à criança brasileira a história do 'bicho', o fantasma; a mulata que ajudou o menino branco brasileiro com seu 'bicho de pé', um tipo de pulga que se esconde sob a pele ou os pés; a negra ou mulata que iniciou o adolescente branco no amor físico. (FREYRE, 1970, p.278)

Através das velhas senhoras negras que serviram de enfermeiras ou babás, as histórias africanas de animais confraternizando com humanos, falando como eles, casando e festejando com eles, foram acrescentadas à coleção de contos Portugueses. A linguagem dos jovens, assim, ficou mais suave através do contato da criança com a ama-de-leite negra. Certas palavras que eram difíceis e soavam estranhas em português tornaram-se muito mais suaves na língua brasileira. (FREYRE, 1970, p.343). 
Nas escolas da época colonial, prevaleciam certas práticas caracterizadas por excessos, turbulências e perversão por parte dos jovens. Havia abuso criminal das fraquezas infantis. Os professores se deleitavam em humilhá-los através de violência corporal. 0 professor era o mestre todo-poderoso. Olhando para baixo em sua cadeira, ele costumava punir com o ar terrível de um latifundiário. Aquele que não se comportasse como deveria, era convidado a ficar de braços estendidos; o que fosse pego rindo em voz alta era humilhado tendo que usar um chapéu de burro para fazer dele o motivo de riso; outro seria forçado a se ajoelhar sobre grãos de milho. Havia também a ponteira e a haste, frequentemente com um espinho ou um alfinete acoplado. (FREYRE, 1968, p.60)

$\mathrm{O}$ patriarcado rural começou a perder sua grandeza com a chegada de Dom João VI ao Rio de Janeiro, em 1808. A descoberta de minas de ouro em Minas Gerais já causava duros golpes a esses patriarcas. O Brasil, então, deixou de ser uma terra de pau-brasil e cana-de-açúcar.

Em Pernambuco, as linhas foram estabelecidas entre a aristocracia do sertão e a burguesia das mansões de Recife. O realinhamento de forças - a burguesia unida com o rei contra os latifundiários que se aliaram aos clérigos - ficou evidente na Guerra dos Mascates (1710), que terminou com a vitória em prol dos interesses urbanos. Os domínios espanhol e holandês de Pernambuco durante 1580-1654 acentuaram ainda mais o desenvolvimento burguês na região. (FREYRE, 1968, p.113).

À medida que a força da burguesia aumentava, também aumentava a união das classes mais baixas. Desenvolveu-se uma irmandade étnica e uma defesa combativa acerca dos direitos dos trabalhadores. Em Palmares, os escravos fugidos organizaram seu próprio estado independente em 1631. Somente os esforços combinados das tropas de várias capitanias puderam destruir esse estado dentro do estado após setenta e seis anos. (FREYRE, 1968, p.39)

A música floresceu na cidade das mansões. Em 1850, quem passasse pelas ruas do Rio de Janeiro ouviria pianos tocados por jovens moças. (FREYRE, 1968, p.42) A vida relativamente fácil nos latifúndios de cana-de-açúcar, já afetada pela descoberta de ouro, declinou ainda mais com o início das plantações de café. Nas cidades, mansões pertencentes aos produtores de açúcar tornaram-se celeiros. Ratos, morcegos e fantasmas tomaram conta dos lares negligenciados. 
À medida que a urbanização aumentava, os pobres começaram a se amontoar em cortiços. Isso começou no Recife holandês. No Rio de Janeiro e Olinda, os pobres viviam em barracos construídos na base dos morros. Os ricos, jesuítas e frades tomaram posse dos morros para construir suas mansões, igrejas e conventos. Para as classes mais baixas restaram buracos malcheirosos, manguezais e pântanos. Barracos tomavam conta da parte baixa da cidade. No entanto, quando os pântanos e as margens foram preenchidos, os ricos desciam das colinas e ocupavam esses lugares da parte baixa também. (FREYRE, 1968, p.134)

Durante os três primeiros séculos de relativo isolamento surgiu o típico brasileiro - o senhor e o escravo. Surgiram também as espécies intermediárias - o mulato. Ele estava começando a se formar na universidade e tornando-se padre, médico etc. Ele tinha seu diploma acadêmico ou militar. Esse era o seu certificado de branquitude. Uma classe média fraca estava surgindo. (FREIRE, 1968, G., p.9).

A divisão da sociedade foi refletida na seguinte composição: (FREYRE, 1968, p.409)

- $\quad$ O homem branco come no salão

- O índio no corredor,

- O mulato na cozinha,

- O negro na privada.

Em 15 de novembro de 1889, em uma 'revolução' pacífica, o imperador foi destronado. No entanto, o republicanismo não desfez o passado. Os novos governantes juraram continuar a política do império. O slogan deles era "ordem e progresso".

A geração dessa época lembra que suas escolas não tinham parquinhos. $O$ uso de Palmatória (bater com folhas de palmeira) foi generalizado. Os alunos recebiam punição pelo menor 'crime'. A maioria dos brancos - homens e mulheres - estava convencida da supremacia branca. (FREYRE, 1970b, p.51-54)

O piano foi difundido nos lares burgueses durante a República. A passagem do salão de concertos para dentro das casas ocorreu quando o piano de cauda se tornou um símbolo de status. Era uma manifestação de bom gosto e prestígio.

Em 1869, o Brasil possuía uma escola primária para 541 crianças nascidas livres. Dentro de cinco anos, a proporção aumentou para 1: 314. Em 1889, o ano da República, subiu para 1:40. (FREYRE, 1970b, p.103) 
Havia aproximadamente 3000 estabelecimentos fabris no país, Pernambuco com 12.000 trabalhadores industriais. A indústria principal era a têxtil. Minas Gerais tinha um número considerável de empresários envolvidos na mineração. Outras indústrias também incluíam bebidas, charuto, cigarro, porcelana, sabão, pólvora, cerâmica, alimentos em conserva e vagões.

Entre 1891 e 1904, Carlos Alberto de Meneses desenvolveu considerável ação social baseada em princípios católicos e ética cristã. Como gerente geral de uma indústria em Pernambuco, ele fez sua empresa incluir princípios do cristianismo social em seus estatutos.

Ele instituiu um programa de serviço social para seus trabalhadores do moinho em Goiana e da fábrica em Camaragibe. Foi por sua iniciativa que se estabeleceu a primeira cooperativa católica no Brasil. Posteriormente, ele reorganizou o programa social da fábrica de Camaragibe em uma grande cooperativa em 1900. Tinha uma gestão mista de trabalhadores e executivos. Ele foi fundamental na formação da Federação dos Trabalhadores Cristãos, que realizou seu primeiro congresso em 1902. Pernambuco era altamente propensa a iniciativas desse tipo. Durante os tempos coloniais, o fourierismo foi propagado na região. E subsequente o socialismo cristão também o fez. (FREYRE, 1970b, p.329)

A economia brasileira sofreu profundas mudanças durante o quarto de século anterior a 1960. o Brasil, um país essencialmente feudal especializado em algumas commodities tropicais mudou para uma economia semi-industrializada. Houve grande concentração da população urbana. Dos 80 milhões de pessoas no país, 35 milhões viviam em centros urbanos. Com o Produto Interno Bruto de 30 bilhões de dólares, o Brasil ficou em onze no ranking das economias mundiais.

As tensões sociais que marcaram o Brasil em meados da década de 1960 foram devido à intensificação do progresso econômico e industrial em um país predominantemente semi-feudal. Apenas três décadas antes da década de 1960, a classe dominante do Brasil era majoritariamente composta por grandes proprietários de terras. A prática da escravidão, que durou quatro séculos, foi substituída por um sistema no qual as relações de trabalho eram marcadas por uma profunda diferença social entre o empregador e o empregado. O sistema representativo, iniciado durante o regime monárquico, continuou durante a República. (FURTADO, 1965, p.17) A partir de 1930, essa estrutura antiga, agrária 
e semi-feudal que serviu de suporte ao sistema político começou a se desfazer. Com o declínio das exportações agrícolas e atividades relacionadas acompanhado do desenvolvimento de um setor industrial urbano, surgiram novas bases para o poder político.

Os empresários industriais e as organizações de trabalhadores começaram a participar de movimentos políticos. No entanto, a eficácia dessas intervenções foi baixa devido à rigidez do quadro institucional. O sistema federal, que prevê representação exclusiva para grandes regiões em detrimento de pequenas regiões menos desenvolvidas, contribuiu para as dificuldades do processo de transição. (FURTADO, 1965, p.18) Além de que a incorporação da classe trabalhadora à atividade política foi dificultada pela lei que dava direito de voto apenas à comunidade alfabetizada. (FURTADO, 1965, p.20)

A população do Nordeste era de 25 milhões na década de 1960. Dois terços deles trabalhavam no campo. Essas pessoas não tinham organizações políticas ou ideia de como exigir melhores condições de vida. Excluídos de relações humanas, sociais e políticas, eles trabalhavam nas plantações de cana-de-açúcar da manhã até à noite. Esse isolamento começou a mudar na década de 1950. O processo de industrialização gerou aumento de renda. O consumo nacional de açúcar passou de 30 milhões de toneladas em 1953/54 para 46 milhões em 1962/63. Isso exigiu aumento da área de cultivo da cana-de-açúcar e, por consequência, houve redução na produção de outros alimentos. (FURTADO, 1965, p.128)

Como resultado desse processo, camponeses chamados de 'moradores', que se dedicavam anteriormente ao cultivo de alimentos, tornaram-se assalariados. Privados de suas terras, essas pessoas se organizaram. Seus movimentos por salários mais altos logo enfrentaram resistência violenta dos proprietários das fazendas. No entanto, os camponeses que se tornaram trabalhadores criaram meios inovadores para se organizar e enfrentar as ameaças das classes proprietárias. Eles transmitiram suas mensagens através de símbolos, comunicados através de canções; criaram mártires em uma terra onde a morte, em qualquer caso, era a finalidade essencial. As ligas camponesas conseguiram, em poucos anos, o que levaria décadas em circunstâncias normais. O que aconteceu na região do Sertão também ocorreu nas zonas intermediárias da Zona da Mata e Caatinga. O Nordeste, em geral, passou por esse aumento dos movimentos sociais. As pessoas exigiam seus direitos inalienáveis como eram concedidos em uma democracia. Elas participaram do processo de transição. 0 analfabetismo os impedia de agir como cidadãos. A filosofia e a pedagogia da alfabetização 
de Paulo Freire emanaram diretamente desse cenário sócio-político. O conceito de conscientização deu voz a essas pessoas. Seu método de alfabetização deu a essas pessoas o direito de escolher seus próprios representantes em uma democracia. (FURTADO, 1965, p.132-3).

\section{EDUCAÇÃO COMO PRÁTICA DA LIBERDADE}

Os conceitos de Freire sobre educação emanam das realidades do Brasil semi-colonial e semi-feudal. Portanto, essas ideias são mais apropriadas às necessidades das pessoas dos países em desenvolvimento. A epistemologia freiriana baseia-se principalmente no processo de alfabetização dos adultos que vivem nessas regiões. Como Karl Marx, que viu na classe trabalhadora das sociedades capitalistas recém-desenvolvidas o principal promotor do progresso social, Freire descobriu, no analfabeto adulto do terceiro mundo, um potencial revolucionário inexplorado no qual ele acreditava que, ao ser aproveitado adequadamente, poderia inaugurar um novo amanhecer nos países em desenvolvimento. Ninguém antes de Freire desenvolveu a base filosófica para a prática educacional de adultos analfabetos. Ele não apenas preencheu essa lacuna; mas sim propôs uma teoria do conhecimento baseada na prática que revolucionou todo o conceito da educação de adultos. Assim, ele eliminou a dicotomia entre teoria e prática. Dada a diversidade das realidades entre os países em desenvolvimento, cada uma marcada por seus diferentes cursos na história, essa epistemologia pode ser específica de uma região ou de um país. Mas a contribuição essencial de Freire reside no fato de que, na maior parte do mundo em desenvolvimento, a teoria e a prática freireanas podem ser adaptadas com sucesso às necessidades e peculiaridades locais.

Elementos essenciais dos conceitos freireanos sobre educação de adultos estão disponíveis em seu livro Educação como Prática da Liberdade. Escrito logo após o golpe militar no Brasil (1964) - enquanto os militares o atacavam por sua filosofia na educação de adultos -, encontramos aqui suas experiências não influenciadas pelo excesso de teorização à época. Ele escreve,

"As experiências como coordenador do Projeto de Educação de Adultos do Movimento pela Cultura Popular de Recife levaram ao amadurecimento precoce das minhas convicções educacionais. Por meio desse projeto, lançamos uma nova instituição de cultura 
popular, um "círculo de cultura", já que entre nós uma escola carregava um conceito tradicionalmente passivo. Em vez de professor, tínhamos um coordenador; em vez de palestras, diálogos; em vez de alunos, participantes do grupo; em vez de um programa de estudos alienados, programas compactos que foram "divididos" e "codificados" em unidades de aprendizagem ".

O leitor observará que aqui o programa é destinado a pessoas que não devem ser "ensinadas", mas sim chamadas para uma discussão. Os participantes não são "estudantes", mas indivíduos que têm muita sabedoria e que merecem uma abordagem digna. 0 "professor" está ausente e, portanto, o modelo hierárquico também. Freire continua:

Nos círculos de cultura, tentamos, através do debate em grupo, esclarecer situações e buscar possíveis ações sobre esse esclarecimento. Os tópicos desses debates eram propostos pelos próprios grupos. Nacionalismo, remessas de lucros para o exterior, evolução política do Brasil, desenvolvimento, analfabetismo, voto para analfabetos e democracia foram alguns dos temas repetidos de grupo para grupo. Esses assuntos e outros foram analisados na medida do possível e apresentados aos grupos com auxílios visuais e na forma de diálogo. (FREIRE, 1998, p. 42-43)

É a partir dessa premissa que Freire desenvolveu seu método de alfabetização. Após seis meses de experiência com os círculos de cultura, "nos perguntamos se não seria possível fazer algo no campo da alfabetização de adultos que nos desse resultados semelhantes ..." (FREIRE, 1998, p. 42). Foi a partir da organização do 'círculo de cultura' que o projeto de alfabetização de adultos evoluiu. A alfabetização era mais um instrumento nas mãos daqueles que discutiam sua realidade individual e social nos círculos de cultura. A alfabetização não era o fim, mas o meio para o esclarecimento da vida humana.

Freire escreve: “Desde o início, rejeitamos a hipótese de um programa de alfabetização puramente mecanicista e consideramos a questão de ensinar os adultos a ler relacionada ao despertar de sua consciência. Queríamos desenhar um projeto no qual tentássemos passar da ingenuidade para uma atitude crítica de modo simultâneo em que ensinássemos a leitura. Queríamos um programa de alfabetização que fosse uma introdução à democratização da cultura, um programa com homens como sujeitos ativos e não como pacientes, um programa que por si só seria um ato de criação, capaz de liberar outros atos criativos, em que os alunos desenvolveriam a impaciência e a vivacidade que caracterizam a pesquisa e a invenção." (FREIRE, 1998, p. 43) 
O método freireano foi baseado no diálogo, que é uma relação pessoal horizontal (FREIRE, 1998, p. 45) e não uma relação vertical ... (FREIRE, 1998, p. 46). “Quem entra em um diálogo o faz com alguém sobre alguma coisa; e esse algo deve constituir o conteúdo de nossa proposta de educação. Sentimos que, mesmo antes de ensinar o analfabeto a ler, poderíamos ajudá-lo a superar sua compreensão fantástica ou ingênua e a desenvolver uma compreensão cada vez mais crítica". (FREIRE, 1998, p. 46)

Freire acrescenta ainda: "É notável ver o entusiasmo de analfabetos que se envolvem no debate e a curiosidade com que eles respondem a perguntas implícitas nas entrelinhas. Na palavra de Odilon Ribeiro Coutinho, esses "homens destemporalizados começam a se integrar no tempo" (FREIRE, 1998, p. 47).

Discutindo trabalho e cultura, Freire escreve: "Os participantes discutindo a cultura como uma aquisição sistemática da experiência humana descobrem que, em uma cultura com letras, essa aquisição não se limita à transmissão oral, como é o caso de culturas que não possuem sinais gráficos. Debatendo a democratização da cultura eles alteram a perspectiva de se adquirir alfabetização." (FREIRE, 1998, p. 48)

Ao elaborar o conceito de 'palavra geradora' e seu impacto sobre os participantes, Freire citou um analfabeto: "Eu tenho a escola do mundo", o que levou o professor Jomard de Brito a perguntar em um ensaio 'O que se pode presumir ao ensinar um adulto que afirma "eu tenho a escola do mundo"?". (FREIRE, 1998, p. 50)

Aqui, encontramos algumas informações valiosas sobre as características práticas e epistemológicas da educação para adultos analfabetos. Primeiramente, Freire sugere "pesquisar o vocabulário do grupo com o qual se está trabalhando". Muitas vezes, o idioma que eles falam e o que leem não tem nada em comum. Freire queria fundamentar a alfabetização na realidade vivida pelo aprendiz adulto. Esse mecanismo fornece à alfabetização de adultos uma base sólida. O conhecimento pertencente ao adulto não pertence a um mundo desconhecido. Os participantes do Círculo de Cultura podem relacionar os tópicos de discussão com sua própria realidade. O movimento de vaivém do texto para o contexto e vice-versa, como Freire explicou em muitos de seus artigos sobre o tema, desenvolve o pensamento crítico dos alunos adultos. A linguagem do discurso encontra um lugar de destaque no texto e, eventualmente, embeleza a própria linguagem. A linguagem do povo comum geralmente é extremamente rica em metáforas e 
ornamentações e com isso rejuvenesce enormemente a chamada linguagem elitista, evitando a sua degradação ocasional. Como uma árvore enraizada no solo, a linguagem é sustentada pelas pessoas comuns e assim é regenerada. Assim, no conceito freireano, a alfabetização de adultos, se realizada adequadamente, pode rejuvenescer a linguagem.

A segunda sugestão de Freire é sobre a seleção das palavras geradoras. Essas palavras devem ser cuidadosamente escolhidas a partir da realidade do aprendiz, para que sirvam não apenas como a porta de entrada para a alfabetização, mas também para a conscientização ou desenvolvimento da consciência crítica. Os seguintes critérios devem reger sua seleção: a) Riqueza fonética b) Dificuldade fonética (as palavras escolhidas devem corresponder às dificuldades fonéticas da língua, colocadas em uma sequência que se move gradualmente de palavras de menor para aquelas de maiores dificuldades); c) tom pragmático, que implica um maior engajamento de uma palavra em uma dada realidade social, cultural e política.

Em terceiro lugar, a criação do que Freire chama de 'codificações' - a representação de variadas situações típicas dos grupos com os quais se trabalha.

Em quarto, a elaboração da agenda que deve servir de mera ajuda para os coordenadores, nunca com horários rígidos a serem obedecidos.

\section{PEDAGOGIA DO OPRIMIDO}

A filosofia e a prática da educação de adultos que Freire apresentou na Educação como Prática da Liberdade foi desenvolvida e cientificamente representada na Pedagogia dos Oprimidos. Este trabalho clássico apresentou toda a gama da filosofia freireana acerca da educação de adultos. Anteriormente, essa educação era sinônimo de alfabetização e desenvolvimento de habilidades. A pedagogia dos oprimidos rejeitou essas noções e as apontou como frágeis e inaceitáveis. Em vez disso, ele elevou a noção a um plano epistemológico. Ele sintetizou elementos de linguística, psicologia, política e filosofia e colocou os analfabetos adultos, que constituem a maioria das pessoas dos países em desenvolvimento, no centro do palco.

O primeiro postulado que ele apresentou foi a caracterização da realidade do terceiro mundo. Seu tema essencial era "opressão". Ecoando Frantz Fanon, o ideólogo da guerra de libertação da Argélia, Freire disse: 


\begin{abstract}
Mesmo que problema da humanização sempre tenha sido, do ponto de vista axiológico, o problema central da humanidade, agora assume o caráter de uma preocupação inevitável. A preocupação com a humanização leva diretamente ao reconhecimento da desumanização, não apenas como uma possibilidade ontológica, mas como uma realidade histórica (...). Mas enquanto humanização e desumanização são alternativas reais, apenas a primeira é a vocação das pessoas. (...) Essa vocação é constantemente negada, mas é afirmada por essa mesma negação. (FREIRE, 1996, p. 25-26)
\end{abstract}

A partir das citações acima, é evidente que Freire universaliza a realidade brasileira na de todo o mundo em desenvolvimento. A partir dessa premissa, ele conclui

(...) a grande tarefa humanística e histórica dos oprimidos: libertar a si mesmos e a seus opressores. Os opressores, que oprimem, exploram e estupram em virtude de seu poder, não conseguem encontrar nesse poder a força para libertar os oprimidos ou a si mesmo. Somente o poder eminente da fraqueza dos oprimidos será suficientemente forte para libertar ambos. (FREIRE, 1996, p. 26)

Assim, o analfabeto adulto não é meramente uma pessoa que deve ser alfabetizada. Na realidade, ele está destinado não apenas a se libertar, mas a toda a sociedade. Como Karl Marx, que atribuiu à classe trabalhadora a tarefa de libertar a si mesma e a sociedade da exploração de classes, Freire apela aos analfabetos adultos para libertar a sociedade da opressão. O analfabeto adulto, segundo Freire, deve ser "conscientizado" para assumir essa tarefa histórica. Mas os oprimidos, devido à natureza contínua do processo de opressão, sofrem da síndrome do "medo da liberdade". Isso às vezes leva alguns membros da classe oprimida a optar pelo papel de opressor ou a desejar opressão, uma vez que a liberdade da opressão é um fenômeno desconhecido para eles. Um dos elementos básicos da relação entre oprimido e opressor é a "prescrição". Toda 'prescrição' representa a imposição da escolha de um indivíduo sobre o outro, transformando a consciência da pessoa prescrita em uma que esteja em conformidade com a consciência do prescritor. Assim, o comportamento do oprimido é o comportamento de um prescritor, seguindo as orientações do opressor. (FREIRE, 1996, p. 28-29)

A auto-depreciação é outra característica dos oprimidos, que deriva da internalização da opinião que os opressores têm deles", diz Freire. "Frequentemente ouvem dizer que não servem para nada, não sabem nada e são incapazes de aprender qualquer coisa, que ficam doentes, preguiçosos e improdutivos, e que no final são convencidos de sua própria incapacidade. (FREIRE, 1996, p. 45) 
Quase nunca percebem que eles também "sabem coisas" que aprenderam em suas relações com o mundo e com outras mulheres e homens. Dadas as circunstâncias que produziram sua dualidade, é natural que desconfiem de si mesmos, comenta Freire. (FREIRE, 1996, p. 45).

Quão naturalmente Freire conecta um fenômeno social, frequentemente observado por membros das classes altas no mundo em desenvolvimento, com a prática educacional dos adultos analfabetos! Freire diz: "Não é raro os camponeses, em projetos educacionais, começarem a discutir um tema gerador de maneira animada, depois param subitamente e dizem ao educador: "Com licença, devemos ficar calados e deixar você falar. Você é quem sabe, não sabemos nada. " Eles costumam insistir que não há diferença entre eles e os animais; quando admitem uma diferença, favorece os animais. "Eles são mais livres do que nós." (FREIRE, 1996, p. 45).

Tendo a relação professor-aluno convencional como 'narrativa' e essa caracterizada como 'conceito de educação bancária', Freire o define como 'um ato de depósito'. Aqui, o professor, em vez de comunicar, publica comunicados e faz depósitos que os alunos pacientemente recebem, memorizam e repetem. (FREIRE, 1996, p. 53) No conceito de educação bancária, o conhecimento é um dom concedido por aqueles que se consideram conhecedores para aqueles que consideram não saber nada. (FREIRE, 1996, p. 53) Freire observa que.

O conceito de educação bancária considera os homens como seres adaptáveis e administráveis. Quanto mais os alunos trabalham para armazenar os depósitos que lhes são confiados, menos desenvolvem a consciência crítica que resultaria na sua intervenção no mundo como transformadores. Quanto mais completamente aceitam o papel passivo que lhes é imposto, mais tendem a se adaptar ao mundo como ele é e à visão fragmentada da realidade depositada neles. (FREIRE, 1996, p. 54)

O conceito freireano pode ser compreendido adequadamente se voltarmos à etimologia. O professor também é referido como o mestre, não apenas do conhecimento, mas da propriedade em geral. Os alunos atuais podem ser atribuídos a alunos da guilda, empregados da casa e escravos na sociedade escravista. Quão naturalmente relacionamos o mestre com o servo e o escravo! Essa relação servil oculta na etimologia também influencia a psique. Caso contrário, como a noção de professor convencional pode ser um objeto de medo, temor e respeito - que não se baseiam no conhecimento do professor, mas no poder? 
Freire vai à raiz desse relacionamento de poder e procura negar essa noção de opressão e a encontra no entendimento humano.

Freire procura reverter a abordagem hierárquica implícita na relação professor-aluno convencional. Ele identifica a comunicação como o meio para alcançá-la. Ele diz

\begin{abstract}
Ainda assim, somente através da comunicação a vida humana pode ter significado. O pensamento do professor é autenticado apenas pela autenticidade do pensamento dos alunos. A professora não pode pensar por seus alunos, nem pode impor seu pensamento a eles. O pensamento autêntico, preocupado com a realidade, não ocorre no isolamento da torre de marfim, mas apenas na comunicação. Se é verdade que o pensamento só tem sentido quando é gerado por resposta à ação do mundo, a subordinação dos alunos aos professores se torna impossível. (FREIRE, 1996, p. 58)
\end{abstract}

Ao proclamar que educação é libertação no sentido real do termo, Freire diz: "Aqueles verdadeiramente comprometidos com a libertação devem rejeitar o conceito de educação bancária em sua totalidade, adotando um conceito de mulheres e homens como seres conscientes ... Eles devem abandonar o objetivo educacional baseado no depositar e substituí-lo pela problematização dos seres humanos e suas relações com o mundo. A educação que coloca problemas, respondendo à essência da consciência ... rejeita os comunicados e incorpora a comunicação." (FREIRE, 1996, p. 60) A educação que propõe problemas, que rompe com os padrões verticais característicos da educação bancária, pode cumprir sua função na prática da liberdade, diz Freire. E aqui ele traz sua noção de 'diálogo'. Ele diz: "Por meio do diálogo, o professor dos alunos e os alunos do professor deixam de existir e um novo termo surge: professor-aluno com alunos-professores. O professor não é mais apenas quem ensina, mas alguém que é ensinado em diálogo com os alunos, que por sua vez, enquanto sendo ensinados, também ensinam. Eles se tornam responsáveis conjuntos de um processo no qual todos crescem. Nesse processo, argumentos baseados em "autoridade" não são mais válidos; para funcionar, a autoridade deve estar do lado da liberdade, não contra ela. Aqui ninguém ensina o outro, nem é autodidata. As pessoas ensinam umas às outras, mediadas pelo mundo, pelos objetos cognoscíveis que na educação bancária são "de propriedade" do professor. (FREIRE, 1996, p. 61)

Assim, Freire formula sua tese de leitura da palavra e do mundo. Ele escreve:

Ao tentarmos analisar o diálogo como um fenômeno humano, descobrimos algo que é a essência do próprio diálogo: a palavra. Mas a 
palavra é mais do que apenas um instrumento que possibilita o diálogo; portanto, devemos buscar seus elementos constitutivos. Dentro da palavra, encontramos duas dimensões, reflexão e ação, em uma interação tão radical que, se uma é sacrificada - mesmo em parte - a outra sofre imediatamente. Não existe uma palavra verdadeira que não seja ao mesmo tempo uma práxis. Assim, falar uma palavra verdadeira é transformar o mundo. (FREIRE, 1996, p. 68)

Freire elabora:

A existência humana não pode ficar calada, nem pode ser nutrida por palavras falsas, mas apenas por palavras verdadeiras com as quais homens e mulheres transformam o mundo. Existir humanamente é nomear o mundo, mudá-lo. Uma vez nomeado, o mundo, por sua vez, reaparece para os nomeadores como um problema e exige deles um novo nome. Os seres humanos não são construídos em silêncio, mas em palavras, em trabalho, em ação-reflexão. (FREIRE, 1996, p. 69)

Esse lócus permite que ele chegue à sua observação clássica sobre o diálogo como:

(...) o encontro entre homens, mediado pelo mundo, para nomear o mundo. Portanto, o diálogo não pode ocorrer entre aqueles que querem nomear o mundo e aqueles que não desejam esse nome - entre aqueles que negam aos outros o direito de falar sua palavra e aqueles cujo direito de falar lhes foi negado. Aqueles a quem foi negado seu direito primordial de pronunciar sua palavra devem primeiro reivindicar esse direito e impedir a continuação dessa agressão desumanizante. (FREIRE, 1996, p. 69)

Caracterizando o diálogo como inexistente na ausência de um profundo amor pelo povo, Freire enfatizou que o diálogo deve se basear no amor, humildade, fé, esperança e pensamento crítico. "Somente o diálogo, que requer pensamento crítico, também é capaz de gerar pensamento crítico. Sem diálogo, não há comunicação e sem comunicação, não pode haver educação verdadeira". (FREIRE, 1996, p. 73-74)

Assim, Freire, como se fosse um truque, colocou a educação de adultos no quadro geral da educação e emite algumas verdades axiomáticas sobre toda a educação. Aqui reside a beleza da análise freireana.

Duas teorizações importantes, com amplas ramificações no contexto social, são expostas em seu artigo 'Ação Cultural pela Liberdade'. A primeira trata da relação das antigas nações colonizadas com os poderes colonizadores. Aqui encontramos Freire efetivamente incorporando o contexto cultural aos elementos econômicos e políticos da tese de Andre Gunder Frank sobre o subdesenvolvimento da América Latina. Freire escreve: 
Do ponto de vista não dualista, pensamento e linguagem, constituindo um todo, sempre se referem à realidade do sujeito pensante. A autêntica linguagem do pensamento é gerada na relação dialética entre o sujeito e sua realidade concreta histórica e cultural. No caso dos processos culturais alienados, característicos das sociedades dependentes ou passivas, a própria linguagem do pensamento é alienada, daí o fato de que essas sociedades não manifestam um pensamento autêntico próprio durante os períodos de sua alienação mais aguda. A realidade tal como é pensada não corresponde à realidade como é vivida, mas corresponde à realidade em que o homem alienado se imagina. Esse pensamento não é um instrumento eficaz, nem na realidade objetiva, com a qual o homem alienado não se relaciona como sujeito pensante, nem na realidade imaginada e almejada. Dissociado da ação implícita no pensamento autêntico, esse modo de pensamento se perde em palavras falsas e ineficazes. Irresistivelmente atraído pelo estilo de vida da sociedade diretora, o homem alienado é um homem nostálgico, nunca verdadeiramente comprometido com seu mundo. Parecer ser e não ser é um dos seus desejos alienados. Seu pensamento e a maneira como ele expressa o mundo geralmente refletem o pensamento e a expressão da sociedade diretora. (FREIRE, 1975, p. 13-14)

A partir dessa percepção da sociedade (anteriormente) colonizada, Freire aborda a situação do indivíduo. Ele escreve:

Um padrão duplo surge. Por um lado, a sociedade culturalmente alienada como um todo depende da sociedade que a oprime e a cujos interesses econômicos e culturais ela serve. Ao mesmo tempo, dentro da própria sociedade alienada, um regime de opressão é imposto às massas pelas elites do poder, que em certos casos são iguais às elites externas e, em outros, são externas transformadas por uma metástase em tipos de poderes domésticos. (FREIRE, 1975, p. 15-16)

Ele elabora a hipótese adiante neste livro. Ele escreve:

Voltemos ao relacionamento entre a sociedade metropolitana e a sociedade dependente como fonte de seus respectivos modos de ser, pensar e expressar. Tanto a sociedade metropolitana quanto a sociedade dependente, totais em si mesmas, fazem parte de um todo maior, o contexto econômico, histórico, cultural e político em que seus relacionamentos mútuos ocorrem. Embora o contexto em que essas sociedades se relacionam seja o mesmo, a qualidade do relacionamento é obviamente diferente em cada caso, sendo determinada pelo papel que cada uma desempenha no contexto geral de sua inter-relação. A ação da sociedade metropolitana sobre a sociedade dependente tem um caráter diretivo, ao passo que a reação dessa ação, de maneira responsiva ou iniciativa, exige um caráter dependente. (...) 'As relações entre o dominador e o dominado', afirma Freire (...) "refletem o contexto social maior, mesmo quando individualmente formal. Tais relações refletem a introjeção de 
mitos culturais do dominador por parte dos dominados. Da mesma forma, a sociedade dependente introjeta os valores e o estilo de vida da sociedade metropolitana, uma vez que esta molda a estrutura formal daquela. Isso resulta na dualidade da sociedade dependente, na sua ambiguidade, no seu ser e no não ser, e na ambivalência característica de sua longa experiência de dependência, rejeitando e sendo atraída pela sociedade metropolitana simultaneamente. (FREIRE, 1975, p. 58-59)

E ele conclui a discussão dizendo que: "A sociedade dependente é, por definição, uma sociedade silenciosa. Sua voz não é uma voz autêntica, mas apenas um eco da voz da metrópole - sob todos os aspectos, a metrópole fala, a sociedade dependente ouve." (FREIRE, 1975, p.59).

Com o colapso da democracia brasileira em 1964, Paulo Freire, como sabemos, foi para o exílio, primeiro na Bolívia e depois no Chile. Depois disso, ele ficou um tempo no México e interagiu com personalidades famosas como Erich Fromm, Ivan Illich etc. Finalmente, após uma breve estadia em Harvard, Freire se estabeleceu em Genebra, onde trabalhou no Conselho Mundial de Igrejas.

\section{PEDAGOGIA EM PROCESSO}

Quando Freire se estabeleceu em Genebra, ele ansiava por trabalhos mais construtivos. As oportunidades surgiram quando um professor brasileiro chamado José Maria Nunes Pereira escreveu a Freire sobre sua discussão com Mario Cabral, ministro da Educação, e Luis Cabral, presidente do recém-independente estado da Guiné-Bissau. Assim, com o tempo, Freire se envolveu com as atividades de alfabetização e pós-alfabetização na Guiné-Bissau, Cabo Verde, São Tomé e Príncipe (1975-77). A correspondência com Luis e Mario Cabral foi publicada em uma coleção chamada Pedagogia em Processo: As cartas à Guiné-Bissau. Freire escreveu uma introdução detalhada, onde se dedicou às várias fases de seu trabalho lá. Em seu prefácio, Jonathan Kozol denominou este livreto como "... Inquestionavelmente o mais acessível ... também o mais poderoso e humano". (KOZOL, 1978, p.4)

Desde o início, Freire enfatizou que "apenas como militantes poderíamos nos tornar verdadeiros colaboradores, mesmo que de maneira muito pequena - nunca como 
especialistas neutros ou como membros de uma missão de assistência técnica estrangeira". (KOZOL, 1978, p.8)

\begin{abstract}
Nós (...) analisamos cuidadosamente a relação", escreveu Freire, "entre alfabetização, pós-alfabetização e produção dentro do plano total da sociedade. Analisamos a relação entre alfabetização e educação em geral. Buscamos uma compreensão crítica do papel que a alfabetização para adultos poderia desempenhar em uma sociedade como a da Guiné, onde a vida das pessoas havia sido afetada direta ou indiretamente pela guerra de independência. A consciência política das pessoas nasceu da luta em si. Enquanto $90 \%$ das pessoas eram analfabetas, no sentido literal do termo, eram altamente politicamente alfabetizadas exatamente o oposto de certas comunidades que possuem um tipo sofisticado de alfabetização, mas que são grosseiramente analfabetas sobre questões políticas. (KOZOL, 1978, p.10)
\end{abstract}

Lembrando sua convicção do passado, formada no Brasil, de que os educadores precisam se reorientar, Freire escreveu: "Ao transformar o sistema educacional herdado dos colonizadores, uma das tarefas necessárias é a formação de novos grupos de professores e a reciclagem de antigos. Entre esses professores ... sempre haverá aqueles que se consideram "capturados" pela velha ideologia e que conscientemente continuarão a adotá-la; eles cairão na prática de minar de maneira oculta ou aberta a nova prática. De tais pessoas, não se pode esperar nenhuma ação positiva em direção à reconstrução da sociedade. Mas haverá outros que, também percebendo-se cativos à velha ideologia, tentarão libertar-se dela através da nova prática à qual irão aderir. É possível trabalhar com essas pessoas. Eles são os que "cometem suicídio de classe". (KOZOL, 1978, p.15)

É preciso lembrar o cenário educacional na Guiné sob o domínio dos portugueses. De 1471 a 1961, apenas 14 guineenses concluíram o ensino superior e 11 o nível técnico. (KOZOL, 1978, p.17) Em dez anos sob o sistema revolucionário, mais pessoas se formaram do que em cinco séculos de domínio português. No ano acadêmico de 1971-72, havia 164 escolas na zona livre, onde 258 professores ensinavam 14.531 alunos.

A tarefa de Freire era experimentar seus métodos de alfabetização entre as pessoas que acabavam de se libertar do domínio colonial português. Por um lado, era necessário dar a devida importância à luta armada que era altamente relevante durante o envolvimento de Freire; por outro, os alunos estavam envolvidos no processo de produção. Portanto, as escolas estavam diretamente ligadas ao dia-a-dia e à luta das pessoas. Freire tentou combinar essas duas necessidades em seu esquema geral de transmitir alfabetização. Freire 
diz: "É imperativo reformular os programas de geografia, história e língua portuguesa, alterando todos os textos literários que estavam impregnados de ideologia colonialista". Era uma prioridade absoluta que os estudantes guineenses estudassem sua própria geografia e não a de Portugal, as enseadas do mar e não o rio Tejo. Era urgente que estudassem sua história, a história da resistência de seu povo ao invasor e a luta por sua libertação. Era necessário que os estudantes guineenses fossem chamados a participar dos esforços em prol da reconstrução nacional. Também era importante começar, talvez timidamente no início, a dar os primeiros passos em direção a uma proximidade entre os alunos do ensino médio de Bissau e o trabalho produtivo. (KOZOL, 1978, p.20)

Paulo Freire e sua equipe, constituída por ativistas e especialistas do Instituto de Ação Cultural (IDAC) e do Conselho Mundial de Igrejas (CMI), tentaram colocar todos esses objetivos em prática. Um vislumbre de tais esforços será encontrado em seu artigo e entrevista intitulada "As pessoas falam sua palavra: alfabetização e ação" e "Alfabetização na Guiné-Bissau revisitada", publicadas na coleção "Alfabetização: lendo a palavra e o mundo".

Paulo Freire diz: “... os materiais desenvolvidos para as fases de alfabetização e pósalfabetização devem ser desafiadores e não condescendentes." (FREIRE, MACEDO, 1987, p.69) Para mostrar como isso foi feito em São Tomé e Príncipe, partes do livro de exercícios e outros textos foram extraídos para este artigo. Freire continua: "A primeira etapa da 'Prática de aprender' é composta por duas codificações (cenários): a primeira, uma foto de uma das belas enseadas de São Tomé, com um grupo de jovens nadando; o segundo, uma foto de uma área rural, com um grupo de jovens trabalhando. Ao lado da figura dos jovens nadando está escrito: "É nadando que se aprende a nadar". Ao lado da figura dos jovens que trabalham está escrito: "É trabalhando que se aprende a trabalhar". E na parte inferior da página: "Ao praticar, aprendemos a praticar melhor". (FREIRE, MACEDO, 1987, p.69)

Vários textos como "Aprender pela Prática", "Natureza da Cultura", "Pensamento Crítico" etc. foram incorporados à apostila. A fase de alfabetização fornece materiais ideais aos adultos para, além de dominar a alfabetização, desenvolver conhecimentos sobre sua própria sociedade e cultura.

Os materiais na fase pós-alfabetização são bastante esclarecedores. Considerando o fato de que a fase anterior deu aos alunos materiais sobre vários aspectos da vida e da luta, 
os materiais de texto na fase pós-alfabetização permitirão que os alunos se concentrem em assuntos mais abstratos. Passagens sobre 'O Ato de Estudar', 'Reconstrução Nacional', 'Trabalho e Transformação do Mundo', 'A luta pela Libertação', 'A Nova Sociedade', 'Trabalho Manual e Intelectual' levam o aluno ao nível de responsabilidade suficiente para debater questões relativas à sociedade e ao mundo. Eles, portanto, podem atuar como sujeitos pensantes amadurecidos. É evidente que aqui, o que Freire alcançou no Brasil nos anos 50 e 60, foi melhorado ainda mais por meio de seu próprio desenvolvimento intelectual e participação de seus colegas. Minha opinião é que todos os escritores de materiais no campo da alfabetização de adultos devem estudar esse material pedagógico desenvolvido por Freire e seus colegas na África antes de se aventurar nesta área.

$\mathrm{Na}$ entrevista acima mencionada, Donaldo Macedo perguntou a Freire se ele havia discutido e avaliado adequadamente a realidade da sociedade na Guiné-Bissau antes de executar seu plano. Freire respondeu afirmativamente. No entanto, ele mencionou que havia problemas linguísticos não resolvidos, já que muitos na Guiné-Bissau, São Tomé e Príncipe não falavam português. Eles falavam sua própria língua. No entanto, essas línguas faladas não haviam desenvolvido nenhuma forma escrita. O crioulo, uma mistura de português e uma ou mais línguas indígenas era predominante em algumas áreas. Freire observou que o crioulo poderia ser usado nessas áreas depois de transformá-lo em sua forma escrita, desenvolvendo sua gramática, sintaxe etc. Foi evidente pela entrevista que a realidade na África era muito mais complexa do que Freire imaginava. Nenhum modelo poderia ser prontamente transplantado e foram necessários anos de pesquisa antes de iniciar esse empreendimento.

A filosofia freireana enfatiza que, embora um adulto analfabeto não tenha o conhecimento dos alfabetizados, ele é altamente conhecedor de assuntos mundanos e, portanto, seu aprendizado de alfabetização deve ser muito diferente do processo de alfabetização da criança. A validade dessa teoria foi eloquentemente explicada nos trabalhos desenvolvidos por Freire na África.

\section{RELEVÂNCIA DE PAULO FREIRE PARA A ÍNDIA}

A teoria e a pedagogia de Paulo Freire para sua aplicação na Índia agora podem ser brevemente explanadas. Movimentos para transmitir alfabetização a indianos analfabetos 
remontam à era do Renascimento de Bengala, em meados do século XIX. Acredita-se que Keshub Chandra Sen, o fiel reformista hindu chamado Brahmosamaj, disponibilizou escolas noturnas para adultos da classe trabalhadora nos anos 1870. (SHASTRI, 1985, p.54) No entanto, foi apenas no contexto da Primeira Guerra Mundial que o movimento recebeu impulso. Escolas noturnas surgiram nas províncias de Bombaim, Bengala e Madras. No estado principesco de Baroda, foram criadas bibliotecas. Algumas instituições educacionais introduziram palestras para a comunidade local. O Movimento Cooperativo, que estava se espalhando pela Índia na época, estava ligado à educação de adultos, especialmente à alfabetização. (BHATTACHARYA, 1984, p.2-3) Os líderes nacionalistas defendiam a causa da alfabetização de adultos enquanto lutavam por obter independência política. Rabindranath Tagore e Mahatma Gandhi exploraram a educação generalista de adultos e a alfabetização em particular. Muitos dos associados e seguidores de Gandhi, incluindo sua esposa Kasturba, estabeleceram escolas nas aldeias para ensinar adultos. (GANDHI, 1969, p.433). Mesmo antes de a Índia conquistar a independência (1947), os governos estaduais, dirigidos pelo Congresso Nacional da Índia, decidiram que a educação de adultos seria de responsabilidade do governo central. (MUKHOPADHYAY, 1994, p.116-130)

No entanto, apesar desse pensamento esclarecido, o cenário de alfabetização na Índia permaneceu sombrio. A porcentagem da população alfabetizada era de 16,10 em 1941 (BHATTACHARYA, 2005, p.94). Após a independência, os governos centrais e estaduais deram mais ênfase à educação de adultos. Mas isso nunca foi considerada uma prioridade. Portanto, com exceção do estado de Kerala, no sul da Índia, a alfabetização permaneceu um problema para a Índia como um todo. À medida que a população aumentava, o número absoluto de pessoas que permaneciam analfabetas era de um número assustadoramente alto. No início dos anos 80 , os indianos constituíam metade da população analfabeta do mundo.

Foi somente durante a década de 1980 que os governos estaduais e central levaram a sério a causa da educação de adultos. Anteriormente, havia controvérsias sobre quais métodos seriam adotados para alfabetizar os adultos. Normalmente, os materiais das crianças também eram usados para os adultos. Isso criou sérios problemas psicológicos entre os analfabetos adultos. 
Os métodos freireanos começaram a ser adotados a partir da década de 1980. A Liga do Serviço Social de Bengala, uma organização iniciada por um associado de Tagore em 1915 (SHYAM, 1997, p.37) começou a produzir material didático em bengali usando os métodos freireanos. Os mesmos métodos também foram aplicados para outras línguas indianas. Aparentemente, sendo as técnicas de Freire extremamente convenientes para adaptação, a porcentagem de alfabetização aumentou bastante nas décadas de 1980 e 1990 (SARKAR, 2003, p.57). Mas como o governo estava mais interessado na técnica freireana do que em sua filosofia de libertação e conscientização, os neoliteratos adultos continuaram a existir como uma subclasse.

Para reverter o cenário, é necessário adotar uma abordagem sintética. A realidade socioeconômica da Índia hoje é muito diferente da do Brasil das décadas de 1950 e 1960. A democracia política é um fato concreto na Índia, embora o conceito não tenha sido aplicado significativamente na vida prática cotidiana da população pobre e marginalizada, que constitui mais de 50\%. O conceito de democracia e iluminação de Grundtvig é muito relevante nesse contexto. Como sabemos, Freire estava ciente do movimento Grundtvigian Folk High School da Escandinávia. (HORTON, FREIRE, 1990, p.21) Ideologias de Tagore e Gandhi, que emanam do solo indiano também são altamente instrutivas a esse respeito. Argumentamos em outro texto como podemos sintetizar os elementos essenciais contidos nos pensamentos de Freire, Tagore, Gandhi e Grundtvig. (BHATTACHARYA, 2005, p.10) Somente uma abordagem sintética é precisa aos indianos neste momento crucial.

\section{REFERÊNCIAS}

BHATTACHARYA, A. Empowering the Neoliterates. Raktakarabi. Calcutta: 1994.

BHATTACHARYA, A. NFS Grundtvig: Educationist Extraordinary. In: SCHJORRING, J.H et al (ed.) Grundtvig Studier. Aarhus University Press. Aarhus: 2005.

BHATTACHARYA, A. Tagore, Gandhi and Freire: Synthesizing Their Educational Thoughts with that of Grundtvig; Viewed from a Third World Perspective. Journal of World Education. Vol. 35, n. 2, 2005.

FREIRE, P. Cultural Action for Freedom, Penguin Books. Middlesex: 1975.

FREIRE, P. Pedagogy of the Oppressed. Penguin Books. Middlesex: 1996. 
FREIRE, P. Education for Critical Consciousness. Continuum. New York: 1998.

FREIRE, P. MACEDO, D. Literacy: Reading the Word and the World. Bergin \& Garvey Publishers. Massachusetts: 1987.

FREYRE, G. The Mansions and the Shanties. Alfred A. Knopf. New York: 1968.

FREYRE, G. The Masters and the Slaves. Alfred A. Knopf. New York: 1970.

FREYRE, G. Order and Progress. Alfred A. Knopf. New York: $1970 \mathrm{~b}$.

FURTADO, C. Diagnosis of the Brazilian Crisis, University of California Press, Berkely. Los Angeles: 1965.

GANDHI, M. K. Selected works, Vol-I, Gandhi Centenary Societ. Calcutta: 1969. (Bengali). HORTON, M. FREIRE, P. We Make the Road by Walking, Temple University Press. Philadelphia: 1990.

KOZOL, J. Foreword in Paulo Freire. In: Pedagogy in Process: The Letters to Guinea Bissau. The Seabury Press. New York: 1978.

MUKHOPADHYAY, K. Tagore's Life and Work, Vol. 4. Visvabharati. Calcutta: 1994. (Bengali).

SARKAR, P. India's Literacy Scenario: Achievements and Failure. In: MITRA, T. (Ed). Education and Development. Jadavpur University. Calcutta: 2003.

ASTRI, S. Ramtonoo Lahiri and Contemporary Bengali Society, Bishwabani Prakashan. Calcutta: 1985. (Bengali).

SHYAM, R. 'Short History of Bengal Social Service League' in Remembering Satyen Moitra. BSSL, Calcutta: 1997 (Bengali).

Recebido em 28 de junho de 2020.

Aprovado em 21 de novembro de 2020

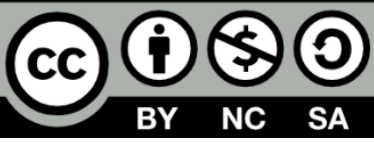

